Int. J. Electrochem. Sci., 11 (2016) $8892-8913$

International Journal of

ELECTROCHEMICAL

SCIENCE

www.electrochemsci.org

\title{
Electrochemical and Quantum Chemical Studies of 1, 5-bis (2- nitrophenyl)-1, 4-pentadien-3-one as Corrosion Inhibitors for Mild Steel in Hydrochloric Acid Solution
}

\author{
R. Sasi kumar ${ }^{1}$, R.Karthik ${ }^{1}$, Shen-Ming Chen ${ }^{1, *}$, P.Prakash $^{2}$, P. Muthukrishnan ${ }^{3, *}$, K.Shankar ${ }^{3}$, \\ A.Kathiresan ${ }^{3}$ \\ ${ }^{1}$ Department of Chemical Engineering and Biotechnology, National Taipei University of Technology, \\ Taipei, Taiwan 106 (ROC) \\ ${ }^{2}$ PG and Research Department of Chemistry, Thiagarajar college, Madurai-625009, India. \\ ${ }^{3}$ Department of Chemistry, Faculty of Engineering, Karpagam University, Coimbatore-641021, India. \\ *E-mail: $\underline{\text { Smchen78@ms15.hinet.net, mukepmk@gmail.com }}$
}

doi: 10.20964/2016.11.10

Received: 8 July 2016 / Accepted: 29 August 2016 / Published: 10 October 2016

Effects of 1, 5-bis (2-nitrophenyl)-1, 4- pentadien -3-one (BPDO) on mild steel in 1M hydrochloric acid solutions were explored using weight loss and electrochemical techniques. Mass losses of polished mild steel in $1 \mathrm{M} \mathrm{HCl}$ measured after diverse time exposure of 2-24h show that the presence of BPDO drastically decreases the rate of mild steel dissolution and the effect enhances upon increasing its concentration. Potentiodynamic polarization experiments demonstrate a large diminish in cathodic, anodic and corrosion currents due to the presence of BPDO in 1M hydrochloric acid. The increase in adsorption of the BPDO on the mild steel surface and reduce of mass transport in the presence of BPDO upon increasing its concentration were confirmed by Electrochemical Impedance spectroscopy (EIS) measurements. The adsorption of BPDO abide Langmuir adsorption model. Activation parameters such as activation energy, enthalpy of activation and entropy of activation were calculated and discussed. Quantum chemical studies were performed to correlate BPDO efficiency and their molecular structure using quantum chemical calculations.

Keywords: Anticorrosion, Corrosion Inhibitor, Electrochemical Impedance spectroscopy, SEM, EDX, Adsorption

\section{$\underline{\text { FULL TEXT }}$}

(C) 2016 The Authors. Published by ESG (www.electrochemsci.org). This article is an open access article distributed under the terms and conditions of the Creative Commons Attribution license (http://creativecommons.org/licenses/by/4.0/). 